\title{
THE 21St ACM NORTH AMERICAN COMPUTER-CHESS CHAMPIONSHIP
}

\author{
November 11-14, 1990, New York \\ The ACM/IEEE Computer Society's Supercomputing Conference scheduled for New York City will host the \\ $21^{\text {st }}$ ACM North American Computer-Chess Championship. The championship will be a five-round Swiss-style \\ event with two rounds on Sunday, November $11^{\text {th }}$, one on Monday, November $12^{\text {th }}$, one on Tuesday, Novem- \\ ber $13^{\text {th }}$, and the final round on Wednesday, November $14^{\text {th }}$. A total of $\$ 8000$ in prizes will be awarded to the \\ authors of the top four finishers. The event will be held in the New York Hilton, the site of the first ACM cham- \\ pionship in 1970.
}

For the first time since the championship began, there has been a major change in the rules. The rate at which moves are required to be made has been changed to the following: each team has two hours to make all its moves. Thus a game will not last more than four hours. This change is expected to make the tournament more enjoyable for the participants and the audience.

In addition to the tournament, a special Endgame Championship will be held testing the capabilities of the programs on certain endgames. Computers have been criticized in the past for their weak endgame play, and this event is expected to illuminate some of the weaknesses. This special event will take place on Monday, November $12^{\text {th }}$ from $9 \mathrm{am}-12 \mathrm{pm}$ and on Wednesday, November, $14^{\text {th }}$ from $9 \mathrm{am}-12 \mathrm{pm}$.

A technical session in which papers are presented on advances in computer chess will be held on Tuesday, November 13th at 10:30am-12:00 noon (see Call for Papers). Tony Marsland will chair the session.

Mike Valvo will serve as Tournament Director. He is one of America's top blindfold chess-players and has served as a Computer-Chess Tournament Director for many years. Danny Kopec will serve as Assistant Tournament Director. Ken Thompson will head the Entries Committee.

For more information or to apply, please write or call: Monty Newborn, School of Computer Science, 3480 University Street, McGill University, Montreal, Quebec, Canada, H3A 2A7 (Tele: 514-398-7079).

\section{TOURNAMENT RULES}

1. Each entry is a computing system and one or more human operators. A listing of all chess-related programs running on the system must be available on demand to the Tournament Director (TD). Each entry requires at least one full-time operator, preferably one of the programmers. One operator cannot assist with more than one entry.

2. Participants are required to attend an organizational meeting at 12 noon on November 11 for the purpose of officially registering for the tournament. Rules will be finalized at that meeting. The TD has the right to choose an alternate to replace an entrant who fails to appear.

3. The tournament is a five-round Swiss-style tournament. The first and second rounds will be played Sunday November 11 at 1:00 PM and 7:00 PM respectively. The third round is scheduled for Monday, November 12 at 1:00 PM, the fourth round for Tuesday November 13 at 1:00 PM, and the final round for Wednesday November 14 at 1:00 PM.

4. Trophies and prizes will be awarded to the first three finishers. The order of finish will be determined by the total number of points earned. If two or more teams have an equal number of points, they will be considered as tied, and the trophies and prizes divided accordingly. A prize of $\$ 3500$ will be awarded to the program which finishes the tournament with the most points, $\$ 2000$ to the second-most, and $\$ 1500$ to the third-most. A trophy and $\$ 1000$ prize will be awarded to the "Best Small Computing System."

5. Unless otherwise specified, rules of play are identical to those of "human" tournament play. If a point is in question, the TD has the right to make the final decision.

6. Games are played at a speed of all moves for each side in two hours. 
7. An operator may ask that the TD stop the clock at most twice during the course of a game because of technical difficulties. The clock must be restarted each time after at most 15 minutes. If an operator using a remote computer can clearly establish that this problems are not in his own computing system but in the communication network, the TD can permit additional time-outs.

8. If a program experiences technical difficulties, the operator can ask the TD for permission to restart the program. When restarting a program after a failure of any kind, the operator must reset all parameters to their values at the time the game was interupted. An operator error made when starting a game or in the middle of a game can be corrected only with the approval of the TD.

9. If an operator types in an incorrect move, the TD must be immediately notified. The clock will be stopped. The game must then be backed up to the point where the error occurred. The clock of the side which made the error is left unchanged while the TD will back up the clock of the other side an amount equal to that lost. The TD may back up the clock of the side in error if it would otherwise force that side to lose the game on time. In this case, the TD will back up the clock of the side in error to give it precisely such an amount of time so as not to lose the game on time control only. If no record is available, the TD will asume each move by the side not in error to have required three minutes. Both sides may adjust program parameters after such an error with the approval of the TD. The TD may allow certain parameters not to be changed, e.g., the contempt factor.

10. Terminals located at the tournament site must communicate directly with remote computers, i.e., there cannot be any human intermediary at the remote location. In cases where there are communication difficulties with remote computers, the TD may disregard this rule.

11. Each team that uses a terminal must position the terminal on the game table in such a way that the opponent has a good view of it. An operator can only (1) type in moves and (2) respond to request from the computer for clock information. If an operator must type in any other information, it must be approved ahead of time by the TD. (This might happen if there is noise on the communication line and, for example, a CR must be typed to clear the line.) The operator cannot query the system to see if it is alive without permission of the TD.

12. A team must receive the approval of the TD to change from one computing system to another.

13. Each game is officially played on a chess-board provided by the Tournament Committee. The official clock is also provided by the Tournament Committee.

14. At the end of each game, each team is required to turn in a game listing to the TD.

NB: Please read rule 3 and 6 carefully. They are very different from the rules in prior tournaments. As a consequence of this, rule 9 also has been reworded.

\section{CALL FOR PAPERS}

In conjunction with the $21^{\mathrm{st}} \mathrm{ACM}$ North American Computer-Chess Championship, there will be a technical session on computer chess. The championship will be held at SUpercomputing'90, a conference jointly sponsored by the IEEE Computer Society and ACM's SIGARCH. Papers will be published in the conference proceedings. Presentations will be 25 minutes. The venue will be the New York Hilton Hotel, New York, NY.

Preferred topics include parallel search techniques, hardware for chess, data structures, transposition tables, and databases, although other areas are also of interest.

Procedure for submitting a paper:

Send five copies to: $\quad$ M. Newborn

School of Computer Science McGill University, Montreal

Quebec, Canada H3A 2AQ7

Deadline for submission: April 15, 1990 